\title{
Induction of apoptosis in human lung carcinoma cells by the water extract of Panax notoginseng is associated with the activation of caspase-3 through downregulation of Akt
}

\author{
SEUNG CHAN PARK ${ }^{1 *}$, HWA SEUNG YOO ${ }^{1 *}$, CHEOL PARK $^{2}$, CHONG KWAN CHO $^{1}$, \\ GI-YOUNG KIM ${ }^{3}$, WUN-JAE KIM ${ }^{4}$, YEON-WEOL LEE ${ }^{1}$ and YUNG HYUN CHOI ${ }^{2,5}$ \\ ${ }^{1}$ Department of East-West Cancer Center, College of Oriental Medicine, Daejeon University, Daejeon 301-724; \\ ${ }^{2}$ Department of Biochemistry and Blue-Bio Industry RIC, Dongeui University College of Oriental Medicine, \\ Dongeui University Graduate School, Busan 614-052; ${ }^{3}$ Faculty of Applied Marine Science, Cheju National University, \\ Jeju 690-756; ${ }^{4}$ Department of Urology, Chungbuk National University College of Medicine, Cheongju 361-763; \\ ${ }^{5}$ Department of Biomaterial Control (BK21 Program), Dongeui University Graduate School, Busan 614-052, Korea
}

Received January 26, 2009; Accepted March 30, 2009

DOI: 10.3892/ijo_00000320

\begin{abstract}
The root of Panax notoginseng is highly valued and commonly used in Oriental medicine. Although recent experimental data have revealed the proapoptotic potency of $P$. notoginseng extracts, the underlying molecular mechanisms of this apoptotic activity have not yet been studied in detail. In the present study, the effects of the water extract of $P$. notoginseng (WEPN) on the growth of human lung carcinoma cells were investigated. It was found that the exposure of A549 and NIC-H460 cells to WEPN resulted in growth inhibition and the induction of apoptosis in a dosedependent manner. The WEPN treatment induced the upregulation of pro-apoptotic Bax, downregulation of antiapoptotic Bcl-2 expression and loss of mitochondrial membrane potential (MMP), which was associated with the proteolytic activation of caspases and the concomitant degradation of poly(ADP ribose) polymerase (PARP) protein. However, the caspase-3-specific inhibitor z-DEVD-fmk blocked PARP degradation and increased the survival rate of WEPN-treated cells. Moreover, the activity of Akt was downregulated in WEPN-treated cells and the phosphatidylinositol-3 kinase (PI3K)/Akt inhibitor LY294002 sensitized
\end{abstract}

Correspondence to: Dr Yung Hyun Choi, Department of Biochemistry, Dongeui University College of Oriental Medicine, Busan 614-052, Korea

E-mail: choiyh@deu.ac.kr

Dr Yeon-Weol Lee, Department of East-West Cancer Center, College of Oriental Medicine, Daejeon University, Daejeon 301-724, Korea

E-mail: lyweol@dju.ac.kr

${ }^{*}$ Contributed equally

Key words: Panax notoginseng, apoptosis, Bcl-2, caspase-3, Akt the cells to WEPN-induced apoptosis through enhancing the activation of caspase- 3 and loss of MMP. The results indicated that the major regulators of WEPN-induced apoptosis in human lung carcinoma cells are the Bcl-2 family and caspase-3, which are associated with mitochondrial dysfunction and dephosphorylation of the Akt signaling pathway.

\section{Introduction}

Ginseng is a medicinal herb consumed worldwide. Over thirteen different species of ginseng have been identified $(1,2)$. Within the Panax genus, P. notoginseng Burk. F.H. Chen (Araliaceae) (Sanqi or Tianqi in Chinese) is a highly valuable and important herb in Oriental traditional medicine for its therapeutic abilities to stop hemorrhaging and to influence blood circulation; it is also the most common drug used to treat chronic liver disease in Korea (2-7). The main root of $P$. notoginseng, called notoginseng, is also known to have many pharmacological activities such as anti-inflammatory and anti-tumor effects and it is also known to alter the functional balance of the immune system $(8,9)$. Recently, many studies have indicated that $P$. notoginseng extracts inhibit the growth and metastasis of various cancer cells in vitro and in vivo that are associated with cell cycle arrest and the stimulation of apoptotic cell death (10-17). However, the precise mechanisms of cell death are largely unknown in human cancer cells.

The regulation of apoptosis, which is a programmed cell death, has become an area of extensive study in cancer research and has been considered an ideal way of eliminating precancerous and/or cancerous cells $(18,19)$. Apoptosis is characterized by a series of distinct morphological and biochemical alterations to cells such as DNA fragmentation, chromatin condensation, cell shrinkage and plasma membrane blebbing. However, most cancer cells can block apoptosis, which allows them to survive despite the genetic and morphological transformations. Therefore, the induction of 
apoptotic cell death is an important mechanism in many anti-cancer drugs $(18,20,21)$. Accumulating data have shown that many chemopreventive and/or chemotherapeutic agents that induce apoptosis target the mitochondria and promote the activation of caspases, which are important proteolytic enzymes responsible for the execution of apoptosis. The caspase-dependent initiation of apoptosis is controlled by a number of regulatory proteins, including members of the Bcl-2 family (22-24). Previous evidence has also shown that phosphatidylinositol-3 kinase (PI3K)/Akt is modulated in response to a variety of stimuli in particular the activation of Akt signaling promotes survival $(25,26)$.

The present study aimed at elucidating the effect of the water extract of $P$. notoginseng (WEPN) in human lung carcinoma cells and the underlying intracellular signal transduction pathways involved in regulating apoptosis. The results of this study demonstrate that WEPN induces caspase-3-dependent apoptosis in human lung carcinoma cells through mitochondrial dysfunction and the Akt signaling pathway.

\section{Materials and methods}

Plant material. P. notoginseng was supplied by Daejeon University Oriental Hospital, Daejeon, Korea. WEPN was prepared in the following manner. Distilled water at $90^{\circ} \mathrm{C}$ was added to dry root $(5 \mathrm{ml} / \mathrm{g})$ and the temperature was maintained for $10 \mathrm{~h}$. The mixture was allowed to cool to room temperature and was then filtered and lyophilized. The yield of the lyophilized residue corresponded to $4.5 \%$ of the original dry root weight and the extract powder was dissolved directly in distilled water.

Cell culture and cell viability study. The human lung carcinoma cell lines A549 and NCI-H460 were obtained from the American Type Culture Collection (Rockville, MD, USA) and cultured in RPMI-1640 medium (Gibco BRL, Gaithersburg, MD, USA) supplemented with $10 \%$ fetal bovine serum (FBS) and $1 \%$ penicillin-streptomycin in a $37^{\circ} \mathrm{C}$ incubator with $5 \% \mathrm{CO}_{2}$. Measurement of cell viability was determined using the 3-(4,5-dimethylthiazol-2-yl)-2,5diphenyl-tetrazolium bromide (MTT, Sigma Chemical Co., St. Louis, MO, USA) assay, which is based on the conversion of MTT to MTT-formazan by mitochondrial enzymes. For the morphological study, the cells were treated with WEPN for $48 \mathrm{~h}$ and photographed directly using an inverted microscope (Carl Zeiss, Germany).

Nuclear staining with DAPI. After treating the cells with WEPN for $48 \mathrm{~h}$, the cells were washed with phosphatebuffered saline (PBS) and fixed with $3.7 \%$ paraformaldehyde (Sigma) in PBS for $10 \mathrm{~min}$ at room temperature. Fixed cells were washed with PBS and stained with 4,6-diamidino-2phenylindole (DAPI, Sigma) solution for $10 \mathrm{~min}$ at room temperature. The cells were washed twice more with PBS and analyzed via a fluorescence microscope (Carl Zeiss).

Protein extraction and Western blot analysis. Cell lysates were lysed in extraction buffer, as previously described (27). The protein concentrations were measured using a Bio-Rad protein assay (Bio-Rad Lab., Hercules, CA, USA) according to the manufacturer's instructions. For Western blot analysis, an equal amount of protein was subjected to electrophoresis on SDS-polyacrylamide gels and transferred by electroblotting to a nitrocellulose membrane (Schleicher \& Schuell, Keene, NH, USA). The blots were probed with the desired antibodies for $1 \mathrm{~h}$, incubated with the diluted enzyme-linked secondary antibody and visualized by enhanced chemiluminescence (ECL) according to the recommended procedure (Amersham Corp., Arlington Heights, IL, USA). The primary antibodies were purchased from Santa Cruz Biotechnology Inc. (Santa Cruz, CA, USA). The peroxidase-labeled donkey anti-rabbit immunoglobulin and peroxidase-labeled sheep anti-mouse immunoglobulin were purchased from Amersham Corp.

Measurement of the loss of mitochondrial membrane potential $\left(M M P, \Delta \Psi_{m}\right)$. To measure the MMP, the dual-emission potential-sensitive probe 5,5 V, 6,6 V-tetrachloro-1,1 V,3,3 V-tetraethyl-imidacarbocyanine iodide (JC-1, Sigma), was used. After treatment with various concentrations of WEPN for $48 \mathrm{~h}$, the cells were scraped from the bottom of the wells and aliquots of $5 \times 10^{5}$ cells were placed into FACS tubes. Cells were then stained with $2 \mathrm{mg} / \mathrm{l} \mathrm{JC}-1$ at $37^{\circ} \mathrm{C}$ for $20 \mathrm{~min}$ and analyzed using flow cytometry (Becton-Dickinson, Heidelberg, Germany).

In vitro caspase activity assay. The caspase activity was determined by a colorimetric assay using caspase- $3,-8$ and -9 activation kits according to the manufacturer's protocol (R\&D Systems, Minneapolis, MN, USA). Briefly, the cells were lysed in a lysis buffer for $30 \mathrm{~min}$ in an ice bath. The supernatants were collected and incubated at $37^{\circ} \mathrm{C}$ with the supplied reaction buffer, which contained dithiothreitol and the substrates Asp-Glu-Val-Asp (DEVD)-p-nitroaniline (pNA) for caspase-3, Ile-Glu-Thr-Asp (IETD)-pNA for caspase-8 and Leu-Glu-His-Asp (LEHD)-pNA for caspase-9. The optical density of the reaction mixture was quantified spectrophotometrically at a wavelength of $405 \mathrm{~nm}$.

Statistical analysis. The data are expressed as mean \pm SD. A statistical comparison was performed using one-way ANOVA followed by a Fisher test. Significant differences between the groups were determined using an unpaired Student's t-test. A $\mathrm{P}$-value $<0.05$ was considered significant.

\section{Results}

Inhibition of cell viability and induction of apoptosis by $W E P N$. In order to determine if WEPN decreases lung cancer cell viability, the A549 and NCI-H460 cells were stimulated with various concentrations of WEPN for $48 \mathrm{~h}$ and the cell viability was measured using the MTT assay. As shown in Fig. 1, the WEPN treatment significantly inhibited the cell viability of both cell lines in a concentration-dependent manner (after $48 \mathrm{~h}$ treatment at $3.2 \mathrm{mg} / \mathrm{ml}$, WEPN decreased the NCI-H460 and A549 cell viability by 74 and $89 \%$, respectively, compared with the controls). Direct observation using an inverted microscope demonstrated that the cells treated with WEPN showed many morphological changes compared with the control cells (Fig. 2A). In particular, cell 


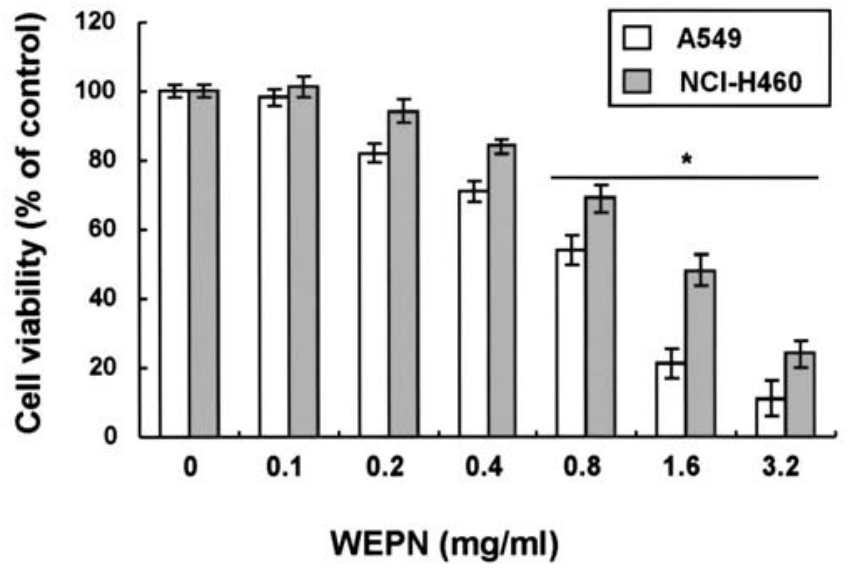

Figure 1. Inhibition of cell viability by the water extract of $P$. notoginseng (WEPN) in A549 and NCI-H460 human lung cancer cells. The cells were seeded at an initial density of $2.5 \times 10^{5}$ cells per $60-\mathrm{mm}$ plate, incubated for $24 \mathrm{~h}$ and treated with various concentrations of WEPN for $48 \mathrm{~h}$. The cell viability was measured using an MTT assay. Each point represents the mean \pm SD of three independent experiments. Significance was determined using a Student's t-test $\left({ }^{*} \mathrm{P}<0.05\right.$ vs. untreated control).

A)

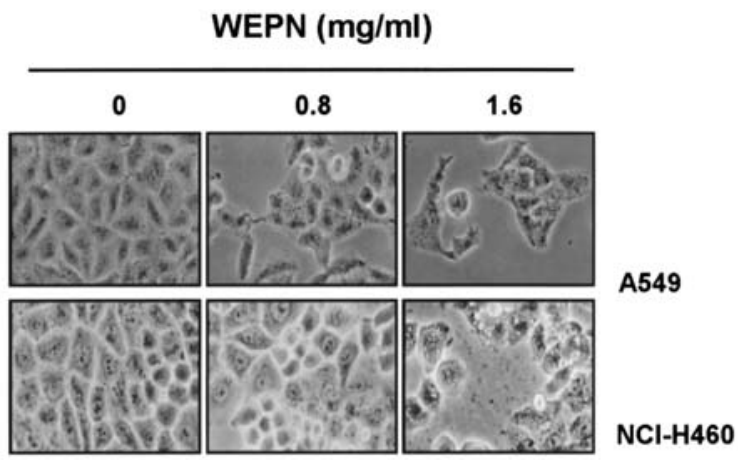

B)

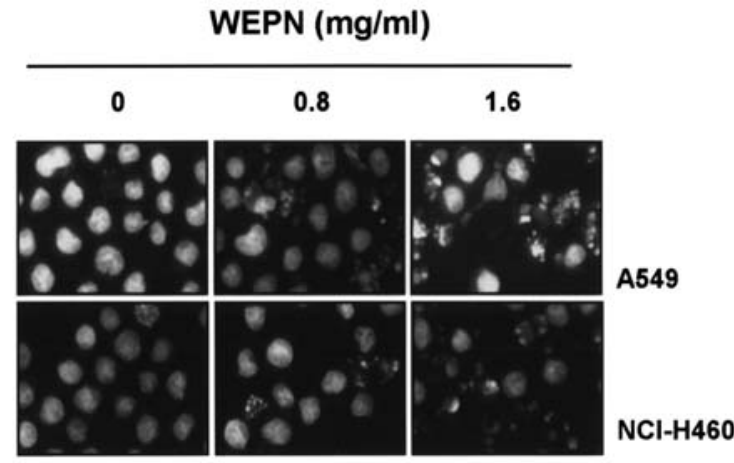

Figure 2. Morphological changes of A549 and NCI-H460 human lung cancer cells due to WEPN treatment. (A) The cells were treated with various concentrations of WEPN for $48 \mathrm{~h}$. The cells were sampled and examined using an inverted microscope (magnification, x200). (B) The cells grown under the same conditions as (A) were sampled, fixed and stained with DAPI. The stained nuclei were then observed under a fluorescent microscope using a blue filter (magnification, $\mathrm{x} 400$ ).

shrinkage, cytoplasm condensation and formation of cytoplasmic filaments appeared after $0.8 \mathrm{mg} / \mathrm{ml}$ WEPN treatment for $48 \mathrm{~h}$. Further experiments using fluorescence microscope analyses were carried out to determine if the
A)

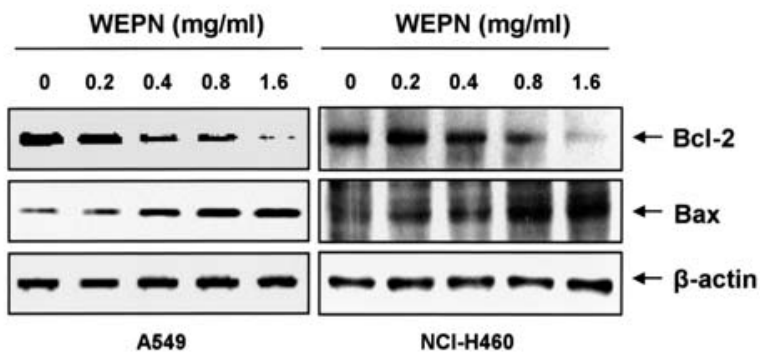

B)

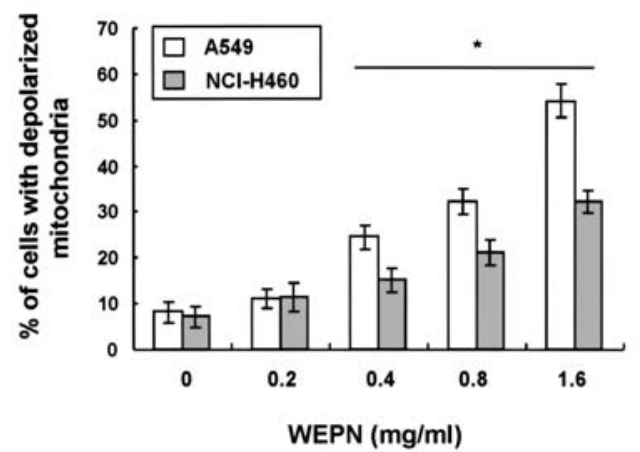

Figure 3. Modulation of anti-apoptotic Bcl-2 and pro-apoptotic Bax protein expression and loss of MMP by WEPN in A549 and NCI-H460 human lung cancer cells. (A) The cells were treated with the indicated concentrations of WEPN for $48 \mathrm{~h}$. Equal amounts of the cell lysates $(30 \mu \mathrm{g})$ were resolved by SDS-polyacrylamide gels, transferred to nitrocellulose and probed with the anti-Bcl-2 and anti-Bax antibodies. Proteins were visualized using the ECL detection system. Actin was used as the internal control. (B) The cells were treated with the indicated concentrations of WEPN for $48 \mathrm{~h}$, stained with $\mathrm{JC}-1$ and incubated at $37^{\circ} \mathrm{C}$ for $20 \mathrm{~min}$. The mean JC-1 fluorescence intensity was detected using a flow cytometer. The results are expressed as the mean \pm SD of three independent experiments. The significance was determined by using the Student's t-test ( ${ }^{*} \mathrm{P}<0.05$ vs. untreated control).

anti-proliferative effect of WEPN is the result of apoptotic cell death. Morphological analysis with DAPI staining showed nuclei with chromatin condensation and the formation of apoptotic bodies in the cells cultured with WEPN in a concentration-dependent manner, in contrast, very few were observed in the control culture (Fig. 2B). These results indicate that the cytotoxic effects observed in response to WEPN are associated with the induction of apoptosis.

Modulation of the expression of Bcl-2 family proteins and loss of MMP by WEPN. To elucidate the mechanisms underlying WEPN-induced apoptosis, the levels of Bcl-2 family proteins were examined using Western blotting. When A549 and NCI-H460 cells were treated with WEPN, a clear decrease in anti-apoptotic Bcl-2 protein expression was observed in a concentration-dependent manner (Fig. 3A). In the case of the pro-apoptotic protein Bax, there was a concentration-dependent upregulation observed in both A549 and NCI-H460 cells treated with WEPN. Next, the MMP was measured in WEPNtreated cells using a fluorescent cationic dye, JC-1, in order to determine whether WEPN-induced apoptosis is associated with the loss of MMP. As shown in Fig. 3B, the exposure of cells to various concentrations of WEPN led to a significant reduction in the level of MMP, indicating that WEPN-induced apoptosis is associated with mitochondrial dysfunction. 
A)

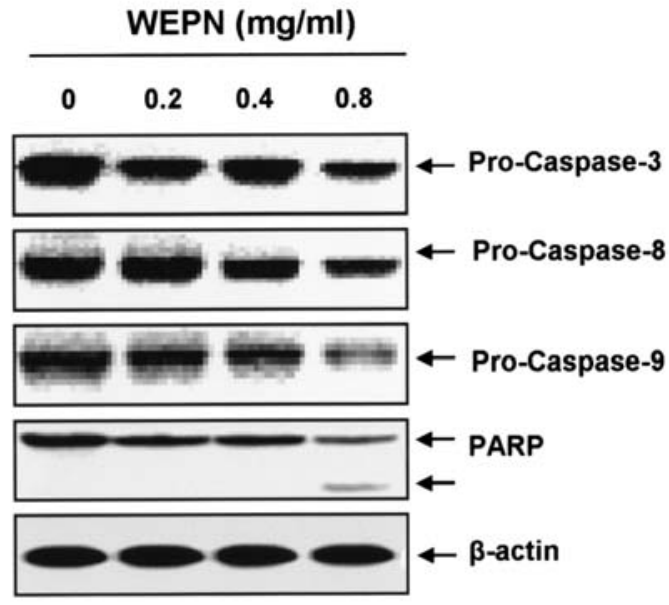

B)

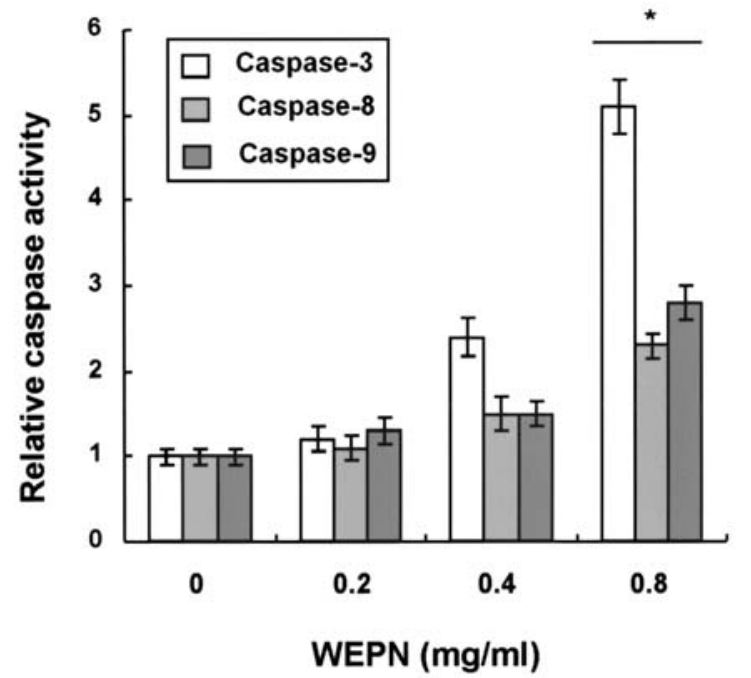

Figure 4. Activation of caspases and degradation of PARP protein due to the WEPN treatment in A549 cells. (A) After 48 h incubation with WEPN, the cells were lysed. The cellular proteins were separated by SDS-polyacrylamide gels and transferred onto nitrocellulose membranes. The membranes were probed with the anti-caspase-3, anti-caspase-8, anti-caspase- 9 and anti-PARP antibodies. The proteins were visualized using an ECL detection system. Actin was used as the internal control. (B) The cell lysates from the cells treated with WEPN for 48 h were assayed for the in vitro caspase-3, -8 and -9 activity using DEVD-pNA, IETD-pNA and LEHD-pNA, respectively, as substrates. The concentrations of the fluorescent products released were measured. The results are expressed as the mean \pm SD of three independent experiments. The significance was determined using the Student's t-test $\left({ }^{*} \mathrm{P}<0.05 \mathrm{vs}\right.$. untreated control).

A)

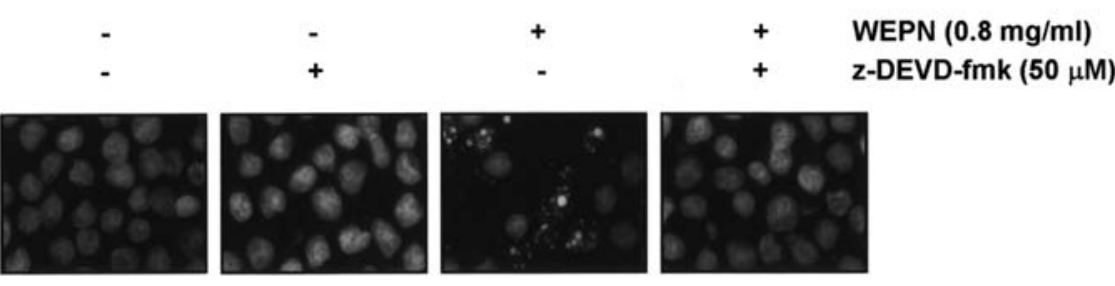

B)

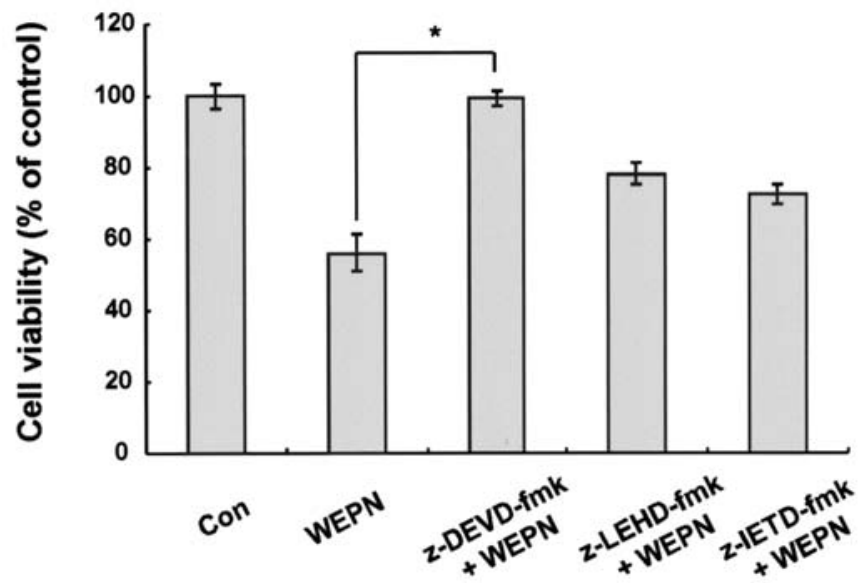

Figure 5. Inhibition of WEPN-induced chromatin condensation and growth inhibition by the caspase-3 inhibitor in A549 cells. (A) The cells were treated with z-DEVD-fmk $(50 \mu \mathrm{M})$ for $2 \mathrm{~h}$ before being challenged with $0.8 \mathrm{mg} / \mathrm{ml}$ WEPN for $48 \mathrm{~h}$. The cells were sampled and stained with DAPI for 10 min and photographed with a fluorescence microscope using a blue filter (magnification, x400). (B) The cells were grown under the same conditions as (A) and the cell viability was measured using an MTT assay. Each point represents the mean \pm SD of three independent experiments. The significance was determined using the Student's t-test ( ${ }^{*} \mathrm{P}<0.05$ vs. untreated control). 
A)

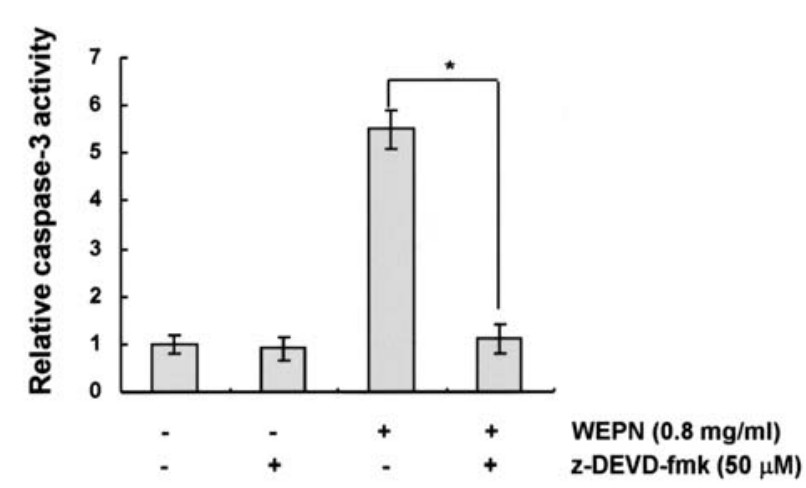

B)

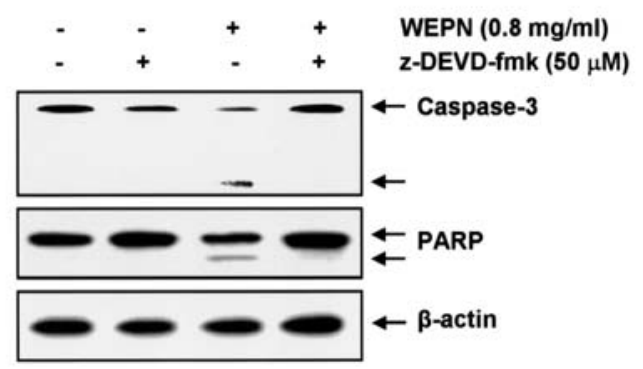

Figure 6. Inhibition of caspase-3 activation and PARP degradation by $\mathrm{z}$ DEVD-fmk, a caspase-3 inhibitor, in WEPN-treated A549 cells. (A) The cell lysates from the cells treated with $\mathrm{z}$-DEVD-fmk $(50 \mu \mathrm{M})$ for $2 \mathrm{~h}$ before being challenged with $0.8 \mathrm{mg} / \mathrm{ml}$ WEPN for $48 \mathrm{~h}$ were assayed for the in vitro caspase- 3 activity using DEVD-pNA. The concentrations of the fluorescent products released were measured. The results are expressed as the mean $\pm \mathrm{SD}$ of three independent experiments. The significance was determined using the Student's t-test $\left({ }^{*} \mathrm{P}<0.05\right.$ vs. untreated control). (B) The cells grown under the same conditions as (A) and equal amounts of the cell lysates $(30 \mu \mathrm{g})$ were resolved by SDS-polyacrylamide gels, transferred to nitrocellulose membranes and probed with the anti-caspase- 3 and anti-PARP antibodies. The proteins were visualized using the ECL detection system. Actin was used as an internal control.

A)

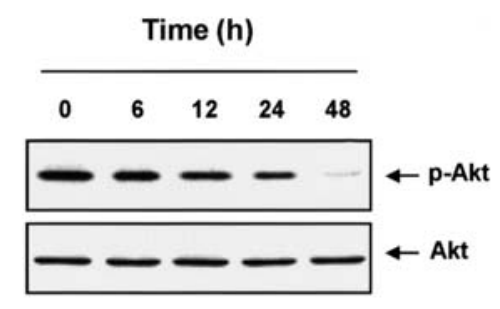

B)

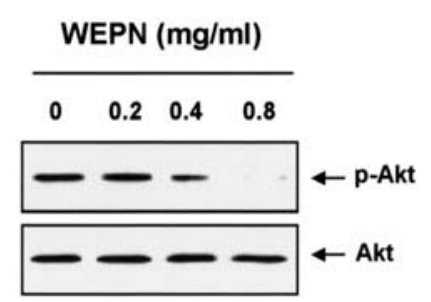

Figure 7. Inhibition of phosphorylation of Akt by WEPN treatment in A549 cells. The cells were treated with $0.8 \mathrm{mg} / \mathrm{ml}$ WEPN for the indicated times (A) or with the indicated concentrations of WEPN for $48 \mathrm{~h}$ (B). Equal amounts of the cell lysates $(30 \mu \mathrm{g})$ were resolved by SDS-polyacrylamide gels, transferred to nitrocellulose and probed with the anti-Akt and anti-p-Akt antibodies. Proteins were visualized using the ECL detection system.
Activation of caspases and degradation of PARP by WEPN. The expression levels and activities of caspase- $3,-8$ and -9 in cells that had been exposed to WEPN were measured in order to determine if WEPN-induced apoptosis is associated with the activation of caspases. As seen in Fig. 4A, Western blot data showed that the levels of pro-caspase-3, -8 and -9 proteins were decreased in a concentration-dependent manner in WEPN-treated A549 cells. In order to further quantify the proteolytic activation of caspases in A549 cells, the lysates equalized for protein from the cells treated with WEPN were assayed for their activities using colorimetric assay kits and it was found that WEPN caused a dose-dependent increase in the proteolytic activities of caspases, especially caspase- 3 (Fig. 4B). Subsequent Western blot analyses showed the progressive proteolytic cleavage of poly (ADP ribose) polymerase (PARP) in A549 cells after WEPN treatment (Fig. 4A), suggesting that the activation of caspase is involved in the WEPN-induced apoptotic pathway.

Inhibition of WEPN-induced apoptosis by a caspase-3 inhibitor. In order to show that the activation of caspases is a key step in the WEPN-induced apoptotic pathway, cells were pretreated with z-DEVD-fmk, z-LEHD-fmk and z-IETD-fmk for $2 \mathrm{~h}$, followed by treatment with $0.8 \mathrm{mg} / \mathrm{ml}$ WEPN for $48 \mathrm{~h}$. The blocking of the caspase- 3 activity by pretreatment of the cells with z-DEVD-fmk prevented the WEPN-induced chromatin condensation and a decrease of cell viability (Fig. 5). Furthermore, z-DEVD-fmk significantly blocked not only caspase-3 activation, but also PARP degradation (Fig. 6). However, the cytotoxic effects of WEPN treatment were not markedly blocked by pretreatment with z-LEHD-fmk and z-IETD-fmk, caspase-8 and -9 inhibitor, respectively. These results clearly show that WEPN-induced apoptosis is associated with the activation of caspase-3.

PI3K/Akt inhibitor sensitizes WEPN-induced apoptosis. The phosphorylation state of the Akt protein in cells after WEPN treatment was examined to determine if WEPN-induced apoptosis is closely related to the Akt signal, which is a downstream effector of PI3K for survival signaling $(25,26)$. As shown in Fig. 7, the levels of the total Akt protein remained unchanged by WEPN treatment; however, its phosphorylation levels were markedly decreased in a time- and dose-dependent manner. Thus, the involvement of Akt signal pathways in WEPN-induced apoptosis was examined using the PI3K/Akt inhibitor LY294002 to determine if the inhibition of Akt phosphorylation was responsible for the induction of apoptosis. As shown in Fig. 8, the combined treatment with WEPN and LY294002 significantly increased the loss of MMP and activation of caspase- 3 and decreased the cell viability resulting from the WEPN treatment. This indicates that WEPNinduced apoptosis is associated with the downregulation of the PI3K/Akt signaling pathway.

\section{Discussion}

Recent studies have reported that the extracts of $P$. notoginseng treatment can cause the accumulation of cells in the G1 or S phase of the cell cycle and apoptosis $(10,12,13)$, which suggests that the growth inhibitory effect of the extracts occur 
A)

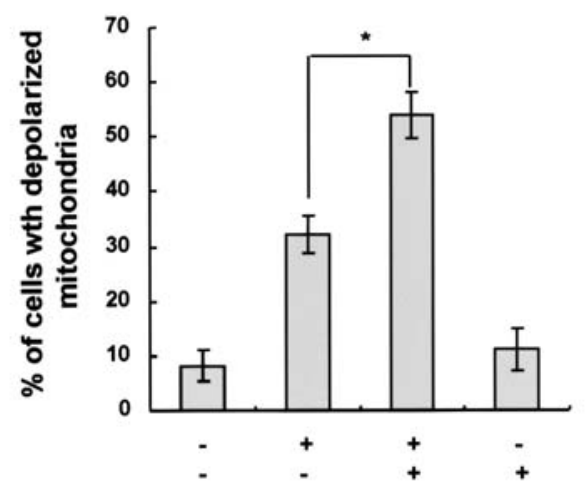

B)

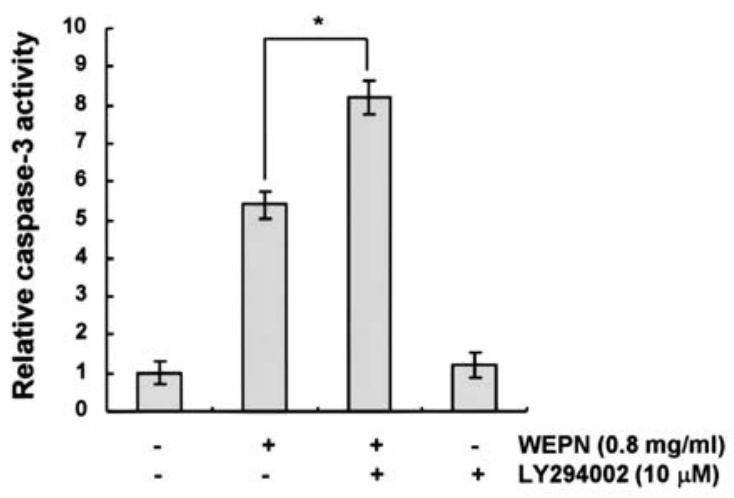

C)

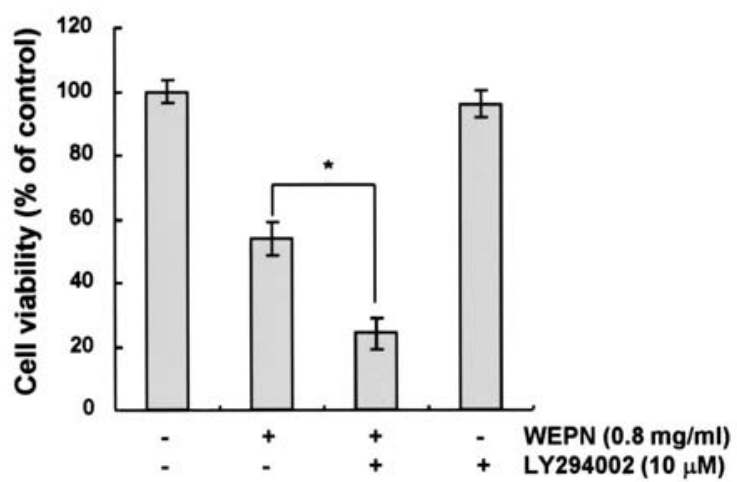

Figure 8. Increase in WEPN-induced cytotoxic effects by the inhibition of the PI3K/Akt signal pathway in A549 cells. (A) The A549 cells were treated with LY294002 $(10 \mu \mathrm{M})$ for $2 \mathrm{~h}$ before being challenged with $0.8 \mathrm{mg} / \mathrm{ml} \mathrm{WEPN}$ for $48 \mathrm{~h}$. The cells were collected, stained with JC- 1 and incubated at $37^{\circ} \mathrm{C}$ for $20 \mathrm{~min}$. The mean JC-1 fluorescence intensity for MMP was detected using a flow cytometer (B and C). The cells grown under the same conditions as (A) were collected and the caspase-3 activity (B) and the cell viability (C) were measured. Each point represents the mean \pm SD of three independent experiments. The significance was determined using the Student's t-test ( $\mathrm{P}<0.05$ vs. untreated control).

through the blockage of the G1 or S phase and that these cells do not enter the G2 phase. While some cell killing mechanisms of these extracts have been suggested $(10,13-15,28)$, little is known about their effects on the growth of human lung cancer cells. Therefore, this study examined whether WEPN induces apoptosis in human lung carcinoma A549 and NCI-H460 cells and the mechanisms related to cell death. In the present study, the WEPN treatment was shown to induce mitochondrial damage and apoptosis in lung carcinoma cells through modulation of the Bcl-2 family proteins and activation of caspase-3. Furthermore, a caspase-3 inhibitor significantly attenuated WEPN-induced apoptosis and the inhibition of the PI3K/Akt pathway enhanced the WEPN-induced cytotoxic and apoptotic effects.

It has previously been proposed that mitochondria are possible targets for anti-cancer drug-induced apoptosis in the death receptor (extrinsic) pathway as well as the mitochondrial (intrinsic) pathway $(20,21)$. Since the discovery of Bcl-2, several mechanisms for the anti-apoptotic properties of this protein have been proposed (22-24). The anti-apoptotic function of Bcl-2 against pro-apoptotic Bax may be explained by its ability to control several key steps involved in death signaling. The Bcl-2 family significantly regulates apoptosis either as an activator ( $\mathrm{Bax}$ ) or as an inhibitor (Bcl-2); therefore, it has been suggested that the $\mathrm{Bax} / \mathrm{Bcl}-2$ ratio is a key factor in the regulation of the apoptotic process $(22,24)$.
The results of this study indicate that WEPN treatment results in significant inhibition of cell viability and the induction of apoptosis in A549 and NCI-H460 cells. The data also showed that WEPN-induced apoptosis was related to augmented levels of the Bax protein and downregulation of Bcl-2, as well as to the loss of MMP in WEPN-treated cells (Fig. 3), which indicates that WEPN increased the $\mathrm{Bax} / \mathrm{Bcl}-2$ ratio and induced mitochondrial dysfunction, leading to apoptosis.

The caspase family of aspartate-specific cystein proteases also plays a critical role in regulating apoptosis. Caspase signaling is initiated and propagated by proteolytic autocatalysis and the cleavage of downstream caspases and substrate proteins $(22,24)$. Caspase- 3 is the most important executioner of apoptosis. Significant evidence indicates that caspase-3 is either partially or totally responsible for the proteolytic cleavage of many key proteins including PARP. PARP is important for cell viability, and the cleavage of PARP facilitates cellular disassembly and serves as a marker of cells undergoing apoptosis (29). In this study, it was demonstrated that WEPN induces apoptosis through the activation of caspase-3 and concomitant degradation of PARP (Fig. 4). This is confirmed by the finding that treatment with WEPN in the presence of z-DEVD-fmk, a specific caspase-3 inhibitor, inhibited the morphological changes and degradation of PARP (Figs. 5 and 6). However, neither caspase-8 (z-LEHD-fmk) nor -9 (z-IETD-fmk) inhibitors markedly blocked the inhibition 
of cell viability by WEPN. These data suggest that WEPNinduced apoptosis is caused by caspase-3-dependent cell death.

Although the PI3K/Akt signal pathways play a critical role in regulating cell survival and death in many physiological and pathological settings, numerous studies have indicated that these pathways are more often associated with cell survival through activation of anti-apoptotic downstream effectors $(25,26)$. Therefore, whether WEPN-induced apoptosis is associated with these pathways was also investigated. WEPN caused the downregulation of Akt activation (Fig. 7) and the combined exposure with LY294002, a PI3K/Akt inhibitor, made the cells more sensitive to WEPN-induced apoptosis by promoting the caspase- 3 activation and mitochondrial dysfunction (Fig. 8). These results indicate that the PI3K/Akt signaling may have a survival role in response to WEPNinduced apoptosis.

In summary, these studies demonstrated that WEPN exposure induced apoptosis in human lung carcinoma cells. The apoptotic response was associated with the increase of Bax, decrease of Bcl-2, mitochondrial dysfunction, caspase-3 activation and PARP degradation. Moreover, the inactivation of Akt may play an important role in WEPN-induced apoptosis. These results provide new information on the possible mechanisms for the anti-cancer activity of WEPN. However, it is still unclear if WEPN can induce apoptosis through other pathways, such as the death receptor pathway or the endoplasmic reticulum pathway. Therefore, more research is necessary to examine the mechanisms for the phosphorylation and activation of multiple apoptosis-related proteins in WEPNinduced apoptosis.

\section{Acknowledgements}

This study was supported by the Korea Science and Engineering Foundation (KOSEF) grant funded by the Korea government (MEST) (PT-ERC, R11-2008-014-00001-0).

\section{References}

1. Harkey MR, Henderson GL, Gershwin ME, Stern JS and Hackman RM: Variability in commercial ginseng products: an analysis of 25 preparations. Am J Clin Nutr 73: 1101-1106, 2001.

2. Ng TB: Pharmacological activity of sanchi ginseng (Panax notoginseng). J Pharm Pharmacol 58: 1007-1019, 2006.

3. Ji W and Gong BQ: Hypolipidemic effects and mechanisms of Panax notoginseng on lipid profile in hyperlipidemic rats. $\mathrm{J}$ Ethnopharmacol 113: 318-324, 2007.

4. Hu LY and Fan YP: Review of study on the mechanism of active ingredients of single Chinese drug in treating intracerebral hemorrhage. Zhongguo Zhong Xi Yi Jie He Za Zhi 26: 376-380, 2006.

5. Park WH, Lee SK and Kim CH: A Korean herbal medicine, Panax notoginseng, prevents liver fibrosis and hepatic microvascular dysfunction in rats. Life Sci 76: 1675-1690, 2005.

6. Lin CF, Wong KL, Wu RS, Huang TC and Liu CF: Protection by hot water extract of Panax notoginseng on chronic ethanolinduced hepatotoxicity. Phytother Res 17: 1119-1122, 2003.

7. Yang XG, Lu B and Guo Y: A review of adverse effects of Panax notoginseng (Burk.) F.H. Chen. Zhong Yao Cai 25: 21621-21628, 2002.

8. Konoshima T, Takasaki M and Tokuda H: Anti-carcinogenic activity of the roots of Panax notoginseng. II. Biol Pharm Bull 22: 1150-1152, 1999.
9. Li Z, He C, Wang C, Cui X, Yu S and Luo W: Studies on control of root rot on Panax notoginseng. Zhong Yao Cai 21: 163-166, 1998.

10. Wang CZ, Xie JT, Zhang B, Ni M, Fishbein A, Aung HH, Mehendale SR, Du W, He TC and Yuan CS: Chemopreventive effects of Panax notoginseng and its major constituents on SW480 human colorectal cancer cells. Int J Oncol 31: 1149-1156, 2007.

11. Wang W, Wang H, Rayburn ER, Zhao Y, Hill DL and Zhang R: 20(S)-25-methoxyl-dammarane-3beta, 12beta, 20-triol, a novel natural product for prostate cancer therapy: activity in vitro and in vivo and mechanisms of action. Br J Cancer 98: 792-802, 2008.

12. Lei Y, Gao Q and Chen KJ: Effects of extracts from Panax notoginseng and Panax ginseng fruit on vascular endothelial cell proliferation and migration in vitro. Chin J Integr Med 14: 37-41,2008.

13. Yan ZC, Chen D, Wu XZ, Xie GR, Ba Y and Yan Z: Effects of aqueous extracts of Aconitum carmichaeli, Rhizoma bolbostemmatis, Phytolacca acinosa, Panax notoginseng and Gekko swinhonis Guenther on Bel-7402 cells. World J Gastroenterol 13: 2743-2746, 2007.

14. Hai J, Lin Q, Lu Y, Zhang H and Yi J: Induction of apoptosis in rat C6 glioma cells by panaxydol. Cell Biol Int 31: 711-715, 2007.

15. Yang ZG, Sun HX and Ye YP: Ginsenoside Rd from Panax notoginseng is cytotoxic towards HeLa cancer cells and induces apoptosis. Chem Biodivers 3: 187-197, 2006.

16. Li JX, Wang ZB, Zhu LQ, Niu FL and Cui W: Apoptosispromoting effect of Panax notoginseng extracts on MNNGtransformed GES-1 cells. Zhong Xi Yi Jie He Xue Bao 3: 123-127, 2005 .

17. Chen PF, Liu LM, Chen Z, Lin SY, Song WX and Xu YF: Effects of ethanol extracts of Panax notoginseng on liver metastasis of B16 melanoma grafted in mice. Zhong Xi Yi Jie He Xue Bao 4: 500-503, 2006.

18. Ghobrial IM, Witzig TE and Adjei AA: Targeting apoptosis pathways in cancer therapy. CA Cancer J Clin 55: 178-194, 2005.

19. Han SI, Kim YS and Kim TH: Role of apoptotic and necrotic cell death under physiologic conditions. BMB Rep 41: 1-10, 2008.

20. Mow BM, Blajeski AL, Chandra J and Kaufmann SH: Apoptosis and the response to anticancer therapy. Curr Opin Oncol 13: 453-462, 2001.

21. Mohamad N, Gutiérrez A, Núñez M, Cocca C, Martín G, Cricco G, Medina V, Rivera E and Bergoc R: Mitochondrial apoptotic pathways. Biocell 29: 149-161, 2005.

22. Jeong SY and Seol DW: The role of mitochondria in apoptosis. BMB Rep 41: 11-22, 2008.

23. Murphy AN, Bredesen DE, Cortopassi G, Wang E and Fiskum G: Bcl-2 potentiates the maximal calcium uptake capacity of neural cell mitochondria. Proc Natl Acad Sci USA 93: 9893-9898, 1996.

24. Thees S, Hubbard GB, Winckler J, Schultz C and Rami A: Specific alteration of the $\mathrm{Bax} / \mathrm{Bcl} 2$ ratio and cytochrome $c$ without execution of apoptosis in the hippocampus of aged baboons. Restor Neurol Neurosci 23: 1-9, 2005.

25. Kennedy SG, Wagner AJ, Conzen SD, Jordan J, Bellacosa A, Tsichlis PN and Hay N: The PI3-kianse/Akt signaling pathway delivers an anti-apoptotic signal. Genes Dev 11: 701-713, 1997.

26. Kim D, Cheng GZ, Lindsley CW, Yang H and Cheng JQ: Targeting the phosphatidylinositol-3 kinase/Akt pathway for the treatment of cancer. Curr Opin Investig Drugs 6: 1250-1258, 2005.

27. Lee W, Choi HI, Kim MJ and Park SY: Depletion of mitochondrial DNA up-regulates the expression of MDR1 gene via an increase in mRNA stability. Exp Mol Med 40: 109-117, 2008.

28. Chung VQ, Tattersall M and Cheung HT: Interactions of a herbal combination that inhibits growth of prostate cancer cells. Cancer Chemother Pharmacol 53: 384-390, 2004.

29. Lazebnik YA, Kaufmann SH, Desnoyers S, Poirier GG and Earnshaw WC: Cleavage of poly(ADP-ribose) polymerase by a proteinase with properties like ICE. Nature 371: 346-347, 1994. 